\title{
Emerging latent fingerprint technologies: a review
}

This article was published in the following Dove Press journal:

Research and Reports in Forensic Medical Science

24 August 2016

Number of times this article has been viewed

\section{Gurvinder Singh Bumbrah \\ Rakesh Mohan Sharma \\ Om Prakash Jasuja}

Department of Forensic Science, Punjabi University, Patiala, Punjab, India
Correspondence: Om Prakash Jasuja Department of Forensic Science, Punjabi University, Patiala 147002, Punjab, India Tel +9l 94 I744 6805

Email opjasuja@gmail.com
Abstract: Information regarding state of the art technology is accessible by searching in a systematic manner, and is the preferred way of keeping up to date. In this review, we present the recent developments in the field of latent fingerprint detection. Recent developments in processing methods including optical, physical, and chemical methods, and sophistical instrumental analytical techniques are presented.

Keywords: latent fingermarks, cyanoacrylate fuming, ninhydrin, small-particle reagent, gas chromatography-mass spectrometry, matrix-assisted laser desorption ionization

\section{Introduction}

Fingerprints are one of the most valuable forms of evidence due to their uniqueness. They are found on objects present at a crime scene and are used to identify the suspect or criminal, and link them to the crime scene, weapon, or object. Fingermarks are formed by sweat released from pores present on the friction ridge skin of hands. Finger ridges contain a large number of sweat pores. When the finger touches any surface, the sweat from these pores gets deposited in form of contours, which are the mirror image of the ridge patterns. Since sweat is colorless in nature, its deposition on a surface also produces colorless impressions, which are called latent fingerprints. ${ }^{1}$

Latent fingerprint residues consist of secretions of the eccrine (sweat), sebaceous, and apocrine glands present on the palm, head, and nose. Sweat contains water $(>98 \%)$, minerals $(0.5 \%)$, and organic compounds $(0.5 \%)$. Eccrine sweat consists of proteins, urea, amino acids, uric acid, lactic acid, sugars, creatinine, and choline, while sebaceous sweat consists of glycerides, fatty acids, wax esters, squalene, and sterol esters. A number of factors associated with the donor such as sex, age, diet, type of disease, medication, and the presence of contaminants on the surface of the fingertips affect the chemical composition of latent finger impressions. Chemical composition of the latent residue further changes with the passage of time due to the evaporation of its volatile constituents, action by microorganisms, and exposure to heat, light, moisture, and air. ${ }^{1-3}$ Popa et $\mathrm{al}^{4}$ observed that biological constituents of fingerprints degraded differently with the passage of time. They also observed that degradation of fingerprints depends on blood group under identical environmental conditions. Exposure of latent fingermarks to common household liquids such as milk, wine, soft drinks, beer, orange juice, and soapy water on a nonporous surface for varying spans of time affects the quality of developed prints. ${ }^{5}$ Different kinds of optical, physical, and/or chemical 
methods are routinely used to visualize latent fingerprints. Optical methods utilize electromagnetic radiation of appropriate wavelengths to visualize latent fingermarks and are nondestructive in nature. The latent finger impressions are developed by physical methods involving physical interaction with deposits of impressions. Chemical methods can be used to develop the latent fingerprints by converting any particular constituent of sweat into a colored derivative. These methods can be used alone or in combination with others to enhance the visibility of developed prints.

The selection of the processing method depends on a number of factors and includes nature (porous, semiporous, and nonporous), texture (smooth and rough), condition (dry and wet), and color of the surface on which the latent fingermark is impinged. The success of detection method also relies on aging of the deposits. ${ }^{1}$

Fieldhouse ${ }^{6,7}$ developed a fingermark "sampler" to maximize the deposition of comparable marks. He studied the effects of variation in force applied, area, angle, and time of contact. He suggested that these factors control the reproducibility and consistency of fingerprints and thus may also affect the quality of the latent fingermarks left at the scene. Staymates et $\mathrm{al}^{8}$ used a microdispensing device to develop artificial fingerprints. This device is capable of depositing a viscous fraction (olive oil, jojoba oil, coconut oil, oleic acid, paraffin wax, and palmitic acid) of residue. Staymates et al also prepared artificial fingermarks on various substrates in a reproducible manner. Daniel ${ }^{9}$ suggested the use of heptane to remove petroleum products such as gasoline from nonporous surfaces before developing oil- or grease-contaminated latent fingerprints.

\section{Optical methods}

The chromatic white light (CWL) sensor generates a topographic image of the sample by using chromatic aberration of light. These sensors are used to localize marks on various nonporous substrates and to separate overlapped fingermarks. ${ }^{10-13}$ These sensors can also be used to estimate the age of latent fingerprints left on a variety of surfaces. ${ }^{14-19}$ Some authors used contactless CWL sensors for determining the age of a fingermark. ${ }^{14-19}$ They observed that different factors such as composition of sweat, humidity, temperature, ultraviolet (UV) radiation, type of substrate, presence of water-containing substance on fingertip, scan resolution, and measured area size affect the results. However, time and pressure of contact between fingertip and substrate are less effective parameters. Dalrymple and Almog ${ }^{20}$ advocated the use of Coherent TracER lasers $(460,532$, and $577 \mathrm{~nm})$ for the visualization of fingerprints developed using IND/Zn, genipin, and lawsone due to their high sensitivity. Nakamura et $\mathrm{al}^{21}$ advocated the use of a portable hyperspectral imager along with continuous-wave green laser over blue or yellow laser for the identification and detection of untreated latent fingermarks or palm prints on the steel and plaster walls. Akiba et $\mathrm{al}^{22}$ measured UV fluorescence obtained by a pulsed Nd-YAG laser to visualize latent fingermarks on a wide range of colored printed papers. Leintz and Bond ${ }^{23}$ used reflected UV to visualize latent fingermarks on corroded brass cartridge casings. Bond ${ }^{24}$ advocated the use of a highintensity UV light source to visualize latent fingermarks on thermal papers.

Lin et $\mathrm{al}^{25}$ used both polarization and specular reflection based on a novel optical method to detect, enhance, and lift latent fingermark images from the sticky side of tape without using any powder or chemicals on surface. However, this method is not applicable for detecting latent fingermarks on highly absorbing and porous surfaces. Kuivalainen et $\mathrm{al}^{26}$ suggested the use of a diffractive element-based sensor for the detection of latent fingermarks on curved smooth objects such as ballpoint pens. They observed that surface roughness or density variation of ridge pattern at certain locations of latent fingermarks affects the quality of image of latent fingermarks. Dubey et $\mathrm{al}^{27}$ suggested the use of full-field swept-source optical coherence tomography for detecting latent fingermarks on poorly reflected smooth, plain surfaces.

Crane et $\mathrm{al}^{28}$ advocated the use of infrared imaging for the detection of untreated latent fingermarks on a wide range of porous and nonporous surfaces without altering or destroying trace evidence present within them. Kirst et $\mathrm{al}^{29}$ used confocal three-dimensional laser microscopy to detect and equalize distorted latent fingermarks and microtraces on nonplanar objects. Pifster ${ }^{30}$ reported the illumination of the surface having suspected fingermarks with the help of specular light using a flat piece of glass at an angle of $45^{\circ}$ to the camera. It was claimed that with the proposed arrangement more light is reflected from the flat surface than that of ridge surface, resulting in brighter furrow area against darker ridges.

\section{Chemical methods}

\section{Small-particle reagent method}

Rohatgi and Kapoor ${ }^{31}$ used alkaline fuchsin-based smallparticle reagent formulation to develop latent fingermarks on wet nonporous surfaces even after 45 days of its deposition. They advocate the utility of this formulation after comparing it with a crystal violet-based similar formulation. Au et $\mathrm{al}^{32}$ used titanium dioxide-based wet powder suspension for the 
development of bloodied marks on dark, smooth, nonporous surfaces. They observed that this composition did not interfere in subsequent presumptive tests for blood. They suggested that this technique should be adopted into standard protocol for enhancement of bloodied prints. They recommended that this procedure should be followed only when subsequent DNA profiling from blood is not required as it reduces the amount of DNA recoverable from developed prints. Choi et $\mathrm{al}^{33}$ used a zinc oxide-based formulation to develop latent fingerprints on a variety of nonporous substrates. They compared powder formulation with smallparticle reagent formulation and observed that small-particle reagent-based formulation gave significantly more effective and better-quality prints than dry powder-based composition, and it was also capable of developing aged latent prints. They also observed that lithium-doped zinc oxide gave more fluorescence than pure zinc oxide. Dhall et $\mathrm{a}^{134}$ used basic zinc carbonate and eosin (B and Y)-based small-particle reagent formulations to develop latent fingerprints on a variety of nonporous surfaces, which were exposed to high temperature $\left(\sim 900^{\circ} \mathrm{C}\right)$ for 1 hour. They observed that the eosin B-based composition gave better quality, intense fluorescence compared to eosin Y-based small-particle reagent formulation.

Ferguson et al $^{35}$ compared different methods (cyanoacrylate fuming, black magnetic powder, ninhydrin, small particle reagent, black powder suspension, and white powder suspension) to develop latent fingerprints on different food items. They observed that black magnetic powder and black powder suspension gave promising results with good quality prints than other methods. Jasuja et $\mathrm{al}^{36}$ used different methods (black powdering, iodine fuming, cyanoacrylate fuming, and small-particle reagent) to develop latent fingermarks on writing surface of compact discs. They observed that after treatment with these techniques, recovery of data and rewriting of data on these treated compact discs vary with its different brands. Jasuja et $\mathrm{al}^{37}$ used natural detergent, instead of a synthetic one, in two small-particle formulations (charcoal powder and basic zinc carbonate based) for the development of latent fingerprints on a variety of surfaces. Saponin, a naturally found surface active compound in the pericarp of the fruit of the Sapindus mukorossi tree, was used in place of synthetic detergent. They observed that the new reagent gave better-quality prints than conventional formulations and worked satisfactorily even after 15 days of its preparation.

Jasuja et $\mathrm{al}^{38}$ compared different small-particle reagent formulations consisting of zinc carbonate (as the suspension material) and six different kinds of fluorescent dyes to develop latent fingermarks on different kinds of nonporous moist surfaces. They recommend the use of cyano blue-based small-particle reagent formulation for the development of latent fingerprints. Sodhi and $\operatorname{Kaur}^{39}$ used basic zinc carbonate and crystal violet (as dye)-based small-particle reagent composition to develop latent fingermarks on moist, nonporous multicolored surfaces.

McDonald et $\mathrm{al}^{40}$ recommended the pretreatment of substrate with volatile bases such as triethylamine or ethanolamine before development of latent fingerprints on acidified nonporous substrates. They also suggested that small-particle reagent or powder dusting procedures can be successfully used for this purpose. However, powder dusting produces increased background noise. Jones et $\mathrm{al}^{41}$ used iron oxidebased powder suspension to develop latent fingermarks on smooth plastic surface to study the effect of topography of substrate surface and observed that topographical feature shape and roughness of surface effect the processing of latent fingermarks and quality of developed prints.

\section{Phase transfer catalyst method}

Jasuja et $\mathrm{al}^{42}$ used Rose bengal and phase transfer catalyst (tetrabutylammonium iodide)-based composition to develop latent fingermarks on the sticky side of adhesive tapes. They were successful in developing old prints (up to 11 days) in addition to fresh prints and observed third level of ridge details in developed prints. Sodhi and $\operatorname{Kaur}^{43}$ used phloxine B (as dye) and tetrabutylammonium iodide (as phase transfer catalyst)based formulation to develop latent fingermarks on a variety of absorbent and nonabsorbent surfaces. Jasuja et $\mathrm{al}^{44}$ used phase transfer catalyst (tetrabutylammonium iodide)-based formulation to develop latent fingerprints on moist, nonporous surfaces. They observed that processing with this formulation gave better-quality prints than cyanoacrylate fuming, smallparticle reagent, or gentian violet methods.

\section{Electrochemical method}

Beresford and Hillman ${ }^{45}$ developed fresh and aged latent fingerprints on stainless steel by electrochemical deposition of an electrochromic polymer such as polyaniline. Sturelle et a ${ }^{46}$ suggested the use of camphor-fuming method over cyanoacrylate, pyrrole electropolymerization, and silver nitrate methods for the development of latent fingermarks on unfired cartridge casings because camphor fuming method is cost effective, nonabrasive, and chances of overdeveloping are less. Jasuja et $\mathrm{al}^{47}$ developed latent fingerprints on a wide range of metallic (zinc, brass, copper, aluminum, steel, and nickel) surfaces by using inorganic aqueous electrolytes. They observed that developed prints are permanent in nature 
and resistant to physical force or rubbing. Bhaloo et $\mathrm{al}^{48}$ observed superior quality of developed prints with gun blue formulation and palladium deposition methods and advocated its use over cyanoacrylate with brilliant yellow processing and electrostatic deposition for the development of latent fingermarks on fired cartridge cases. Liu et $\mathrm{al}^{49}$ suggested the use of a neutral solution of electrolytes to develop latent fingerprints on cartridge cases as it does not affect the subsequent microscopic examination of cartridge cases.

\section{lodine fuming method}

Jasuja and Singh ${ }^{50}$ developed high-quality permanent prints without any background coloration by using iodine fuming method to process latent fingermarks (fresh and aged) on thermal papers. They suggested that permanent prints may be developed due to oxidation of leuco dyes (present in surface of thermal paper) by iodine. Jasuja et al ${ }^{51}$ used an aqueous solution of brucine to fix latent fingerprints developed by iodine fuming method on both porous and nonporous surfaces.

\section{Dye-based methods}

Braasch et al $^{52}$ suggested the inclusion of Nile red in development sequence after using physical developers for processing latent fingermarks (fresh and aged) on a variety of wet papers. Thomas and Farrugia ${ }^{53}$ used genipin and lawsone to enhance bloody fingerprints present on papers of different colors and porosities. They suggested that neither of these reagent-based formulations is suitable for the enhancement of blood-contaminated fingerprints on different kinds of papers. They recommended the use of the ninhydrin method over these reagents to develop such fingerprints after comparing all these agents. Frick et al ${ }^{54}$ used aqueous Nile blue reagent for the detection of latent fingermarks on porous (white copy paper) and nonporous surfaces. They suggest the use of polylight to improve the contrast of developed prints because photoluminescence is produced by developed prints due to the presence of Nile red in composition. An aqueous solution of Nile blue gives dark blue color with acidic components, while it gives pink or red color with neutral lipids. They found that the presence of trace amounts of Nile red in Nile blue is responsible for photoluminescence effect produced by the developed prints. Fritz et $\mathrm{al}^{55}$ used ethyl acetate and petroleum spirit-based $p$-dimethylaminocinnamaldehyde formulation to develop latent fingermarks on different kinds of papers including thermal paper. Dominick et $\mathrm{al}^{56}$ developed latent fingerprints on nonporous surfaces (glass and ceramic) exposed to high temperatures by using different formulations.
They observed that superglue followed by Brilliant Yellow 40 (BY40) is the most effective procedure for developing latent fingerprints at all temperatures. They noticed that this procedure is effective only for dry surfaces. However, they suggested vacuum metal deposition procedure for developing latent fingerprints on wet, nonporous surfaces. Badiye and Kapoor $^{57}$ developed latent fingermarks on a variety of porous, semiporous, and nonporous (both single-colored and multicolored) surfaces using Robin ${ }^{\circledR}$ blue powder. Dominick and Laing ${ }^{58}$ advocated the potential utility of cyanoacrylate fuming followed by Gun Blue followed by BY40 and treatment with cyanoacrylate fuming followed by palladium deposition for developing latent fingermarks on unfired cartridge cases after comparing them with cyanoacrylate fuming, followed by BY40, Gun Blue only, black powder suspension, and palladium deposition only. They suggested that treatment of nonporous surface with a specific metal-based composition enhances the efficiency of procedure. Rawji and Beaudoin ${ }^{59}$ advocated the use of Oil Red $\mathrm{O}$ method for the development of latent fingermarks on moist porous surfaces (thermal and white standard paper) after comparing it with physical developer method.

Reynolds et $\mathrm{al}^{60}$ and Jones et $\mathrm{al}^{61}$ analyzed two titanium dioxide-based fingerprint powders of different brands using scanning as well as transmission electron microscopy and $\mathrm{X}$-ray photoelectron spectroscopy. They suggested that presence, thickness, and composition of coats over titanium dioxide particles and its adherence to these particles affect the performance of powders in development of latent fingermarks on a variety of surfaces including adhesives. Trapecar ${ }^{62}$ used different methods (powder, cyanoacrylate, and small-particle reagent) to develop latent fingermarks (fresh and aged) on moist glass and metal surfaces. He suggested that the quality of developed prints depends on the method of development and on the time of exposure of the surface to water.

Honig and $Y_{0 a k}{ }^{63}$ advocated the use of Oil Red $\mathrm{O}$ for the development of latent fingermarks on moist porous surfaces after comparing it with ninhydrin and physical developer methods. Piekny and Knaap ${ }^{64}$ advocated the use of ABC-type dry chemical fire extinguisher for the development of latent fingerprints on different kinds of substrates. The composition enables the development of high-quality prints in a rapid and efficient manner after fogging in a room. Petretei and Ang$\mathrm{yal}^{65}$ advocated the use of Hungarian Red for the development of bloody fingerprints on skin after comparing it with amido black and leucocrystal violet powders. Perry and Sears ${ }^{66}$ used Natural Yellow 3 (curcumin) for the development of latent fingermarks on naturally weathered metals and rigid plastics. 
They suggested that Natural Yellow 3 can be used in place of Solvent Black 3 and it can be introduced into the standard processing sequence for enhancing the ridge details.

Richards and Thomas ${ }^{67}$ compared different fluorescent dye stains and observed that Basic Yellow in 2-propanol, MRM-10, and MBD gave better-quality prints than Ardrox, RAM, and Rhodamine $6 \mathrm{G}$ on different surfaces such as aluminum cans, metal gun magazines, glass, glossy paper, plastic bags, finished wood, and unfinished wood. Zampa et $\mathrm{al}^{68}$ used Fast Blue B ( $O$-dianisidine bis (diazotized) zinc double salt) to develop cannabis-contaminated fingerprints (fresh and aged) on a wide range of nonporous and porous surfaces. Sodhi et $\mathrm{al}^{69,70}$ used Rhodamine B, fluorescene, and phloxine B-based powder compositions to develop latent fingermarks on a wide range of porous and nonporous surfaces (including multicolored surfaces). They suggested that these compositions are useful in developing weak prints due to their fluorescent nature and can be used along with an intense light source such as the Crimescope or Lumiscope to develop better-quality prints. Frick et $\mathrm{al}^{71}$ suggested the inclusion of Oil Red O (in propylene glycol) into the processing sequence after treatment with 1,2-indanedione and followed by treatment with physical developer for the development of fresh latent fingerprints on porous surfaces as it increases the efficiency of the sequence and also the quality of developed prints. Simmons et $\mathrm{al}^{72}$ compared different processing methods (physical developer, Oil Red O, and modified physical developer) to develop latent fingerprints (fresh and aged) on moist porous surfaces (white paper, cardboard, and leaflets). They used Tween 20 in place of Synperonic- $\mathrm{N}$ in the modified physical developer for enhancing latent fingerprints. They suggested the use of the physical developer and the modified physical developer over Oil Red $\mathrm{O}$ for processing such types of substrates.

Bentolila et $\mathrm{al}^{73}$ developed blood-contaminated fingerprints on different kinds of fabrics by using alginate gel in combination with amido black. They observed that the gellifting technique is useful for processing blood-contaminated fingerprints on dark-patterned synthetic silk. Aronson ${ }^{74}$ used amido black-based formulation to develop bloody prints collected on the sticky side of duct tape in a homicide case. de Puit et $\mathrm{al}^{75}$ advocated the addition of the physical developer into standard processing sequence for the development of latent fingermarks on different kinds of porous surfaces. Beaudoin $^{76}$ suggested the use of Oil Red O, followed by Rhodamine $6 \mathrm{G}$ for the development of latent fingermarks on moist, dark, absorbent substrates. Gaskell et al ${ }^{77}$ developed grease-contaminated latent fingerprints on dark nonporous surfaces using Natural Yellow 3-based formulation. Olenik ${ }^{78}$ suggested treatment with cyanoacrylate vapors before staining with Basic Yellow 40 to develop latent fingermarks on the adhesive as well as the smooth side of duct tape. Fitzi et al ${ }^{79}$ provided an updated processing sequence after comparing 19 development techniques for the visualization of latent fingerprints on thermal papers. Fritz et $\mathrm{al}^{80}$ observed less sensitivity of dry contact $p$-dimethylaminobenzaldehyde method than ninhydrin method for the enhancement of latent fingerprints on porous surfaces. They suggested the use of a cost-effective LED light source instead of more expensive Rofin Polilight for the visualization of latent fingerprints on remote locations. Beaudoin ${ }^{81}$ advocated the use of orthotolidine for the visualization of blood-based fingermarks on pig skin after comparing it with amido black.

\section{Cyanoacrylate fuming method}

Babin $^{82}$ used cyanoacrylate fuming method to develop latent fingermarks on bullet casings. Schwarz and Hermanowski ${ }^{83}$ observed that humidity has negligible effects on long-term storage of nonporous items before applying cyanoacrylate fuming method for the detection of latent fingermarks on them. Fieldhouse ${ }^{84}$ advocated the use of cyanoacrylate fuming method for the development of latent fingermarks (fresh and aged) on textured and smooth plastics. Takatsu et $\mathrm{al}^{85}$ suggested the use of vapors of $p$-dimethylaminobenzaldehyde to enhance the cyanoacrylate-fumed latent fingermarks on solvent-sensitive surfaces such as oil marker writings and materials with rough surfaces such as unglazed earthenware. Ristova et $\mathrm{al}^{86}$ suggested the exposure of glass-bearing age-degraded latent fingermarks to UV radiations for their enhancement prior to cyanoacrylate fuming method. Bentolila et $\mathrm{al}^{87}$ synthesized and used fluorescent monomers in cyanoacrylate fuming method for developing latent fingermarks on glass surface. Prete et $\mathrm{al}^{88}$ used a novel luminescent cyanoacrylate such as lumicyano to develop latent fingerprints on glass and a number of semiporous and nonporous surfaces in a single processing step without any further treatment. Paine et $\mathrm{al}^{89}$ observed that quality of developed prints and microstructure of the polycyanoacrylate depend on relative humidity during cyanoacrylate fuming. They also observed that relative humidity has less influence on sebaceous marks. Nixon et a ${ }^{90}$ suggested the use of valine-based powders prior to cyanoacrylate fuming to develop latent fingermarks (aged) on black polyvinyl chloride. They observed that degradation of latent fingermarks also depends on moisture. Montgomery et $\mathrm{al}^{91}$ and McLaren et $\mathrm{al}^{92}$ suggested the pretreatment of cyanoacrylate-developed prints with methylamine solution 
to improve the quality of developed prints on a wide range of surfaces including polyethylene. Hahn and Ramotowski ${ }^{93}$ developed high-quality fluorescent prints on a wide range of nonporous surfaces using one-step fluorescent cyanoacrylate fuming method. Wilson ${ }^{94}$ suggested the use of RAY (Rhodamine, Ardrox, Basic Yellow) dye stain, gentian violet, and alternate powder for developing latent fingermarks on the adhesive side of tape after cyanoacrylate fuming.

\section{Nanoparticles method}

Cai et $\mathrm{al}^{95}$ developed latent fingerprints on various nonporous surfaces with an alkaline solution of highly fluorescent watersoluble cadmium-telluride quantum dots, which were capped with mercaptosuccinic acid in very short time, ie, 1-3 seconds. Wang et $\mathrm{al}^{96}$ developed latent fingerprints on the sticky side of adhesives by using CdSe nanoparticle-based suspension. They suggested that incorporation of CdSe nanoparticles in a formulation not only enhances the intensity of fluorescence but also reduces the background noise by a significant order. Arshad et $\mathrm{al}^{97}$ prepared zinc oxide-silicon dioxide nanopowder for the development of latent fingerprints on various kinds of nonporous surfaces. They used it as a dry powder as well as a small-particle reagent suspension (without water) for developing prints on dry and wet surfaces. They advocated the use of this powder for the development of latent fingermarks as it revealed excellent third-level ridge details with minimal background staining. Theaker et $\mathrm{al}^{98}$ prepared and used novel hydrophobic silica-based nano- and microparticles to develop latent fingermarks (fresh and aged) on different nonporous surfaces. Sametband et $\mathrm{al}^{99}$ synthesized petroleum ethersoluble gold nanoparticles and quantum dots functionalized by $n$-alkanethiols and $n$-alkaneamine for the development of latent fingermarks. They suggested that the use of hydrophobic-capped gold nanoparticles instead of Ag-PD alone enhances the intensity and quality of the developed prints. Song et $\mathrm{al}^{100}$ used poly(styrene-alt-maleic anhydride)- $b$ polystyrene-functionalized gold nanoparticles in conjunction with photoacoustic imaging for developing latent fingermarks on a wide range of surfaces and observed that high-quality developed prints are useful for studying third-level ridge details. Algarra et al $^{101}$ used fluorescent cadmium-selenide sulfide nanoparticles functionalized with thiolated porous phosphate heterostructures to develop latent fingermarks on a wide range of porous and nonporous surfaces.

\section{Ninhydrin and its analogs}

Yang and Lian ${ }^{102}$ developed latent finger impressions on porous and nonporous surfaces by using solid-medium ninhydrin in a nondestructive manner. The results with this method are better than traditional methods for the development of latent finger impressions. Almog et al ${ }^{103}$ developed and used a premixed solution containing ninhydrin and metal salts of group IIb (such as zinc and cadmium chloride) for the development of latent fingermarks on paper. They observed higher sensitivity of this reagent as compared to genipin in the shorter wavelength domain. Levinton-Shamuilov et a ${ }^{104}$ used genipin for the development of latent fingermarks on different kinds of papers and observed that genipin gave better-quality prints than ninhydrin or DFO on papers with high-luminescent backgrounds. Jelly et al ${ }^{105}$ developed purple-brown fingerprints with red luminescence on paper surface using substituted naphthoquinones. Coughlan ${ }^{106}$ advocated the use of acetone to reduce the masking caused by common pen ink in the development of latent fingermarks by ninhydrin on paper. Schwarz et al ${ }^{107}$ observed that the addition of molecular sieve in stock solution of DFO increases its shelf life and did not affect the quality of developed prints. Goel ${ }^{108}$ suggested the use of 1,2-indanedione-zinc chloride dry contact method over hot print system for the development of latent fingerprints on thermal paper as the former provides better-quality prints, which never fades with passage of time. Jasuja et al $^{109}$ suggested that pressure applied to deposit fingermarks and the donors sweat affect the quality of prints developed by ninhydrin method on white bond paper. Chen et $\mathrm{al}^{110}$ suggested the use of ninhydrin and 1,2-indanedione to develop latent fingermarks on thermal papers.

\section{Conventional and nonconventional powders}

Garg et al ${ }^{111}$ developed latent fingerprints on a variety of porous, semiporous, and nonporous surfaces with white cement as well as with conventional white powder. They observed that treatment with white cement does not interfere with data contained in compact discs. They successfully developed fingerprints on carbon paper even after 40 days of deposition with white cement. Garg et al ${ }^{112}$ and Kumari et $\mathrm{al}^{113}$ used turmeric powder and gulal (used as a festival color) to develop latent fingermarks on a wide range of surfaces. Singh et $\mathrm{al}^{114}$ advocated the use of the powdering method over the iodine fuming method to develop latent fingermarks on fruits (banana, orange, apple, and guava) and vegetables (potato, onion, and tomato). They observed that the quality of developed prints varied with the condition of fruits and vegetables. Scott ${ }^{115}$ observed better contrast in prints developed by phosphorescent powder than more traditional fluorescent techniques. Ma et al ${ }^{116}$ suggested the 
use of sodium yttrium tetrafluoride doped with erbium and ytterbium (NaYF4:Er, Yb; as dry and wet powder) over the cyanoacrylate fuming method for the development of latent fingermarks on luminescent and nonluminescent, nonporous surfaces. Gurbuz et al $^{117}$ suggested that the particle size of the fingerprint powder and porosity of surface affect the contrast and background staining and quality of developed prints.

Mopoung and Thongcharoen ${ }^{118}$ developed and used activated carbon fingerprint powder, derived from banana peel, to develop latent fingermarks on glass. They suggested the use of high amounts of mineral oil and sodium acetate in the composition as it significantly improves the adherence capability of the powder composition. Low et $\mathrm{al}^{119}$ used acid-modified Imperata cylindrica powder for developing latent fingermarks (fresh and aged) on paper, plastic, glass, and metal surfaces. This formulation was also useful in developing latent fingermarks that were submerged in water for up to 72 hours. However, the sensitivity and quality of Imperata cylindrica powder were found to be lower than that of Sirchie black powder.

\section{Instrumental methods}

\section{Thin-layer chromatography}

Bramble $^{120}$ used thin-layer chromatographic technique to separate lipid and nitrogenous components of latent fingerprints. He observed that DFO and ninhydrin react with watersoluble components, while physical developers react with water-insoluble components of latent fingerprint residues.

\section{Gas chromatography-mass spectrometry} Weyermann et $\mathrm{al}^{121}$ studied the effect of aging on composition of fingerprints by gas chromatography-mass spectrometry (GC-MS) for the purpose of dating fingermarks and observed that contents of initial composition were higher on porous surfaces than on non-porous surfaces. They observed that concentration of squalene decreases at a faster rate on non-porous surfaces. They suggested that relative peak area of squalene to cholesterol can be used to estimate the time of deposition of latent fingerprint residues. Michalski et al ${ }^{122}$ analyzed the latent fingermark residues by GC-MS and found significant variation in ratios of fatty acids and their corresponding methyl esters between donors of different sex and race, and suggested that these ratios of several fatty acid methyl esters can be used to differentiate individuals of different sex and race. Koenig et al ${ }^{123}$ analyzed the wax esters fraction of latent fingerprint residue using GC-MS to determine the age of latent fingermarks. Croxton et $\mathrm{al}^{124}$ simultaneously analyzed the amino acid and fatty acids fractions of latent fingermark residues by GC-MS. They suggested that a solvent system consisting of sodium hydroxide, ethanol, and pyridine in a ratio of 75,40 , and $10(\mathrm{v} / \mathrm{v})$ was most effective for their extraction from nonporous substrates. Michalski et al defined several fatty acid ratios in latent fingerprint residues by GC-MS. They suggested that ratios of several fatty acid methyl esters could be used to differentiate individuals of different sex and race. Girod and Weyermann ${ }^{125}$ analyzed lipid components of fingerprint residues using GC-MS and classified donors into two main groups "poor" and "rich" using hierarchical cluster analysis. They found that hypercholesterolemia and acne affect the contents of lipids. They observed that pretreatment of data significantly reduces inter- and intravariability in data.

\section{Liquid chromatography-mass spectrometry}

Mangle et al $^{126}$ quantified the composition of amino acids using 1,2-indanedione-zinc chloride and ninhydrin with liquid chromatography-mass spectrometry. They also suggested that paper should always be treated with 1,2-indanedione-zinc chloride first, followed by ninhydrin. de Puit et $\mathrm{al}^{127}$ used liquid chromatography-mass spectrometry to analyze the amino acid fractions of latent fingermark residues.

\section{Raman spectrophotometry}

Connatser et al ${ }^{128}$ used surface-enhanced Raman spectroscopy (SERS) to visualize fingermarks by focusing on lipids and amino acid components of residues. In SERS, analytes are in contact with metal nanoparticles. Song et al ${ }^{129}$ suggested the use of antibody-functionalized silver nanoparticles to target specific sweat components, followed by SERS imaging. However, Guicheteau et $\mathrm{al}^{130}$ suggested the functionalization of nanoparticles with a Raman probe, ie, 4-mercaptobenzoic acid, to optimize visualization of latent fingermarks. They also used semiautomated Raman-based chemical imaging procedure to visualize fingermarks and to identify prohibited substances present in the secretions (eg, drugs and explosives). Raman spectrophotometry does not interfere with subsequent treatment of latent fingermarks with cyanoacrylate.

\section{Infrared spectrophotometry}

Williams et al ${ }^{131}$ analyzed the latent fingerprint residue obtained from children of age ranging from 2 to 11 years. Infrared microspectrophotometry was performed and it 
was observed that carboxylic acid salts are more stable than esters. They also observed the variation between the composition of children's and adult's fingerprint residues on the basis of relative ratios between main components of residues such as carboxylic acid salts, esters, and proteins. They suggested the adoption of these types of detection techniques, which are target specific in nature, to detect fingermarks of children. Fritz et a ${ }^{132}$ analyzed the lipid contents of latent fingerprint residues by employing infrared microscopy to determine the sex and age of the donor. They observed that lipid contents of latent fingerprint residues do not vary significantly with sex and age of donor. They also observed the significant loss in the lipid composition of residues within 3 months of its deposition. Williams et al ${ }^{133}$ analyzed specific chemical components of latent fingerprint residues by infrared microspectroscopy. They preferred the reflection-absorption mode over the attenuated total reflection mode for the analysis of latent fingerprint residues due to the absence of appreciable signals in the attenuated total reflection mode. They observed rapid change in composition of latent fingerprint residues of children compared to adults. They also observed the rapid disappearance of latent fingerprints of children compared to adults.

\section{Capillary electrophoresis-mass spectrometry}

Atherton et a $\mathrm{l}^{134}$ identified and quantified amino acids in latent fingerprint residue by employing capillary electrophoresismass spectrometry. They observed that serine and glycine are most abundant amino acids in fingerprint residues.

Girod et a $1^{135}$ provided up-to-date information about the composition of the fingerprint residue (fresh and aged) in their review paper. They also discussed the effects of different factors such as type and condition of substrate, environmental conditions, and detection techniques for the development of latent fingerprints. Bailey et $\mathrm{al}^{136}$ compared different instrumental techniques to analyze and characterize chemical composition of fingerprint residues and developed a protocol for their analysis using these techniques.

Almog et al ${ }^{137}$ correlated palmar moisture with "quality" of the donor's fingerprint. They showed that the palmar moisture level was not the key factor affecting the donorship for amino acid reagents. Lambrechts et al ${ }^{138}$ investigated the origin of autofluorescence of latent fingerprints and observed that tryptophan and its metabolites along with pheophorbide $A$ are responsible for the autofluorescence produced by latent fingerprints.

\section{Laser desorption ionization time-of-flight mass spectrometry}

Emerson et al ${ }^{139}$ analyzed triacylglycerols and other constituents of fingerprint residues by using laser desorption/ionization time-of-flight mass spectrometry to investigate the use of cosmetics and to determine the sex from fingerprint residues. No sex-specific variation is observed in triacylglycerols and other constituents of fingerprint residues.

\section{Matrix-assisted laser desorption ionization mass spectrometry}

In matrix-assisted laser desorption ionization mass spectrometry (MALDI-MS), fingerprints need to be covered with a specific UV-absorbing matrix before performing the analysis. A two-step matrix application method, which is commonly known as "dry-wet" method, is used. In this method, the matrix is first dusted with a-cyano-4-hydroxycinnamic acid onto the sample and then sprayed with solvent. ${ }^{140,141}$ However, curcumin can also be used as matrix in place of a-cyano-4-hydroxycinnamic acid for MALDI-MS analysis. The curcumin is a solvent-free, natural-colored matrix. ${ }^{142}$ Bradshaw and Francese ${ }^{143}$ advocated the utility of matrix-assisted laser desorption ionization tandem mass spectrometry imaging in analyzing oleic acid constituent of latent fingermarks. They recommended the presence of multiple ion products of species under investigation to identify it. Bailey et a $\mathrm{l}^{144}$ detected cocaine and its metabolites benzoylecgonine and methylecgonine in latent fingerprints with MALDI-IMS-MS-MS (after 3 months of deposition) and secondary ion mass spectrometry (after 1 month of deposition). They observed the poor sensitivity of secondary ion mass spectrometry, but its selectivity is better than MALDI and dark energy spectroscopic instrument mass spectrometry. Francese et al ${ }^{145}$ reviewed the utility of MALDI-MSI to visualize latent fingermarks. MALDI-MSI used characteristic ion signals generated from endogenous species, such as amino acids and lipids, of residues to visualize fingermarks, metabolites, and contaminants such as condom lubricant or drug. ${ }^{146-151}$ Ferguson et al ${ }^{152}$ determined the sex of a fingermark donor by using MALDI-MS, with a success rate that varies from $67.5 \%$ to $85 \%$. Multivariate modeling of mass spectrometric profiles of fingermark peptides and small proteins contained in the secretions is used to determine the sex of donor.

\section{Conclusion}

Conventional methods of latent fingermark detection are useful for visualization and development of fingermarks on a wide 
range of substrates. However, they are nonspecific in nature and more research is required to better understand the reaction mechanism involved in these reactions and to develop new, effective, and sensitive reagents for processing latent fingermarks (aged and degraded) on difficult and unusual surfaces. No single technique is ideal for processing all kinds of surfaces, and new, sensitive and efficient methods are being developed for enhancing latent fingermarks on different types of surfaces. A trend in the examination of latent fingermarks has been observed. With the advent of highly sophisticated instrumentation instead of new development methods, emphasis on analyzing the sweat residue was given to determine the dietary habits and other traits of the individual to whom the latent belongs. These techniques have been found useful for chemical imaging of latent fingerprint residues and provide valuable information regarding sex and drug habits of donors from latent deposits. Although these techniques provide in-depth information regarding chemical composition of latent fingermark residue in much less time, we cannot ignore conventional methods for developing latent fingermarks in any instance.

\section{Disclosure}

The authors report no conflicts of interest in this work.

\section{References}

1. Champod C, Lennard C, Margot P, Stoilovic M. Fingerprints and Other Ridge Skin Impressions. $1^{\text {st }}$ edition. CRC Press LLC, 2004.

2. Lee HC, Gaensslen RE. Advances in Fingerprint Technology. $2^{\text {nd }}$ edition. CRC Press LLC, 2001.

3. Siegel JA, Knupfer GC, Saukko PJ. Encyclopedia of Forensic Sciences. $2^{\text {nd }}$ edition. Academic Press, 2013.

4. Popa G, Potorac R, Preda N. Method for fingerprints age determination. Rom J Leg Med. 2010;2:149-154.

5. Maslanka DS. Latent fingerprints on a nonporous surface exposed to everyday liquids. J For Ident. 2016;66:137-154.

6. Fieldhouse S. Consistency and reproducibility in fingermark deposition. Forensic Sci Int. 2011;207:96-100.

7. Fieldhouse S. A comparison of fingermark deposition methodology. Fingerprint Whorld. 2011;37:94-101.

8. Staymates JL, Staymates ME, Gillen G. Evaluation of a drop-ondemand micro-dispensing system for development of artificial fingerprints. Analytical Methods. 2013;5:180-186.

9. Daniel R. Pretreatment processing for nonporous items coated with gasoline. J For Ident. 2013;63:165-173.

10. Qian K, Schott M, Schone W, Hildebrandt M. Separation of highresolution samples of overlapping latent fingerprints using relaxation labeling. In SPIE - Optics, Photonics, and Digital Technologies for Multimedia Applications II, Brussels, Belgium, 2012:84361 A-1/84361 A-9.

11. Jankow M, Hildebrandt M, Sturm J, Kiltz S, Vielhauer C. Performance analysis of digital cameras versus chromatic white light (CWL) sensors for the localization of latent fingerprints in crime scenes. In SPIE - Optics, Photonics, and Digital Technologies for Multimedia Applications II, Brussels, Belgium, 2012:84360X-1/84360X-15.

12. Kiltz S, Hildebrandt M, Dittmann J, Vielhauer C. Challenges in contact-less latent fingerprint processing in crime scenes: review of sensors and image processing investigations. In $20^{\text {th }}$ European Signal Processing Conference (EUSIPCO 2012), Bucharest, Romania, 2012: 1504-1508.
13. Makrushin A, Hildebrandt M, Fischer R, Kiertscher T, Dittmann J, Vielhauer C. Advanced techniques for latent fingerprint detection and validation using a CWL device. In SPIE - Optics, Photonics, and Digital Technologies for Multimedia Applications II, Brussels, Belgium, 2012:84360V-1/84360V-12.

14. Merkel R, Gruhn S, Dittmann J, Vielhauer C, Brautigam A. On non-invasive $2 \mathrm{D}$ and $3 \mathrm{D}$ chromatic white light image sensors for age determination of latent fingerprints. Forensic Sci Int. 2012;222: $52-70$.

15. Merkel R, Brautigam A, Kraetzer C, Dittmann J, Vielhauer C. Evaluation of binary pixel aging curves of latent fingerprint traces for different surfaces using a chromatic white light (CWL) sensor. In 13th ACM Workshop on Multimedia and Security, Buffalo/Niagara Falls, NY, 2011: 41-50.

16. Merkel R, Breuhan A, Hildebrandt M, Vielhauer C, Brautigam A. Environmental impact to multimedia systems on the example of fingerprint aging behavior at crime scenes. In SPIE - Optics, Photonics, and Digital Technologies for Multimedia Applications II, Brussels, Belgium, 2012:1-16.

17. Merkel R, Dittmann J, Vielhauer C. How contact pressure, contact time, smearing and oil/skin lotion influence the aging of latent fingerprint traces: first results for the binary pixel feature using a CWL sensor. In IEEE International Workshop on Information Forensics and Security (WIFS), Iguacu Falls, 2011:1-6.

18. Merkel R, Gruhn S, Dittmann J, Vilhauer C, Brautigam A. General fusion approaches for the age determination of latent fingerprint traces: results for 2D and 3D binary pixel feature fusion. In SPIE Three-Dimensional Image Processing (3DIP) and Applications II, Burlingame, California, USA, 2012:1-16.

19. Merkel R, Pocs M, Dittmann J, Vielhauer C. Proposal of non-invasive fingerprint age determination to improve data privacy management in police work from a legal perspective using the example of Germany. In Data Privacy Management and Autonomous Spontaneous Security, Pisa, Italy, 2013:61-74.

20. Dalrymple B, Almog J. Comparison of latent print detection using semiconductor laser and LED light sources with three chemical reagents. J For Ident. 2012;62:14-27.

21. Nakamura A, Okuda H, Nagaoka T, Akiba N, Kurosawa K, Kuroki K, Ichikawa F, Torao A, Sota T. Portable hyperspectral imager with continuous wave green laser for identification and detection of untreated latent fingerprints on walls. Forensic Sci Int 2015;254:100-105.

22. Akiba N, Saitoh N, Kuroki K, Igarashi N, Kurosawa K. Visualizing latent fingerprints on color-printed papers using ultraviolet fluorescence. J Forensic Sci. 2011;56:754-759.

23. Leintz R, Bond JW. Can the RUVIS reflected UV imaging system visualize fingerprint corrosion on brass cartridge casings postfiring? J Forensic Sci. 2016;61:219-225.

24. Bond JW. A noninvasive and speculative method of visualizing latent fingerprint deposits on thermal paper. J Forensic Sci. 2015;60:1034-1039.

25. Lin S, Yemelyanov KM, Pugh EN, Engheta N. Polarization-based and specular-reflection-based noncontact latent fingerprint imaging and lifting. J. Opt. Soc. Am. A. 2006;23:2137-2153.

26. Kuivalainen K, Peiponen KE, Myller K. Application of a diffractive element-based sensor for detection of latent fingerprints from a curved smooth surface. Meas. Sci. Technol. 2009;20:077002-077004.

27. Dubey SK, Mehta DS, Anand A, Shakher C. Simultaneous topography and tomography of latent fingerprints using full-field sweptsource optical coherence tomography. J. Opt. A: Pure Appl. Opt. 2008;10:015307-015314.

28. Crane NJ, Bartick EG, Perlman RS, Huffman S. Infrared spectroscopic imaging for noninvasive detection of latent fingerprints. J Forensic Sci. 2007;52:48-53.

29. Kirst S, Clausing E, Dittmann J, Vielhauer C. A first approach to the detection and equalization of distorted latent fingerprints and microtraces on non-planar surfaces with confocal microscopy. Proc SPIE 8546, Optics and Photonics for Counterterrorism, Crime Fighting and Defense VIII 85460A; 2012. 
30. Pifster R. The optical revelation of latent fingerprints. Fingerprint Whorld. 1985,10:64-70.

31. Rohatgi R, Kapoor AK. Development of latent fingerprints on wet non-porous surfaces with SPR based on basic fuchsin dye. Egypt $J$ Forensic Sci. 2015, http://dx.doi.org/10.1016/j.ejfs.2015.05.007.

32. Au C, Jackson-Smith H, Quinones I, Jones BJ, Daniel B. Wet powder suspensions as an additional technique for the enhancement of bloodied marks. Forensic Sci Int. 2011;204:13-18.

33. Choi MJ, McBean KE, Ng PHR, McDonagh AM, Maynard PJ, Lennard $\mathrm{C}$, Roux C. An evaluation of nanostructured zinc oxide as a fluorescent powder for fingerprint detection. J Mater Sci. 2008;43:732-737.

34. Dhall JK, Sodhi GS, Kapoor AK. A novel method for the development of latent fingerprints recovered from arson simulation. Egypt J Forensic Sci.. 2013;3:99-103.

35. Ferguson S, Nicholson L, Farrugia K, Bremner D, Gentles D. A preliminary investigation into the acquisition of fingerprints on food. Sci Justice. 2013;53:67-72.

36. Jasuja OP, Singh GD, Sodhi GS. Development of latent fingerprints on compact disc and its effect on subsequent data recovery. Forensic Sci Int. 2006;156:237-241.

37. Jasuja OP, Singh GD, Sodhi GS. Small particle reagent: A saponin based modification. J For Ident. 2007;57:244-251.

38. Jasuja OP, Singh GD, Sodhi GS. Small particle reagents: Development of fluorescent variants. Sci Justice. 2008;48:141-145.

39. Sodhi GS, Kaur J. A novel fluorescent small particle reagent for detecting latent fingerprints on wet non-porous items. Egypt J Forensic Sci.. 2012;2:45-47.

40. McDonald D, Pope H, Miskelly GM. The effect of chlorine and hydrogen chloride on latent fingermark evidence. Forensic Sci Int. 2008; 179:70-77.

41. Jones BJ, Downham R, Sears VG. Effect of substrate surface topography on forensic development of latent fingerprints with iron oxide powder suspension. Surf. Interface Anal. 2010, 42, 438-442.

42. Jasuja OP, Singh GD, Sodhi GS. Development of latent fingerprints on the sticky side of adhesive tapes: Phase transfer catalyst-based formulation. Canadian Society of Forensic Science Journal. 2007;40: $1-13$.

43. Sodhi GS, Kaur J. Fingerprint detection using phloxine B dye. J For Ident. 2003;53:8-13.

44. Jasuja OP, Kumar P, Singh G. Development of latent fingermarks on surfaces submerged in water: optimization studies for phase transfer catalyst (PTC) based reagents. Sci Justice 2015;55:335-342.

45. Beresford AL, Hillman AR. Electrochromic enhancement of latent fingerprints on stainless steel surfaces. Anal Chem. 2010;82:483-486.

46. Sturelle V, Cominotti C, Henrot D, Desbrosse X. The use of camphor in the development of latent prints on unfired cartridge casings. $J$ For Ident. 2006;56:694-705.

47. Jasuja OP, Singh K, Kumar P, Singh G. Development of latent fingermarks by aqueous electrolytes on metallic surfaces: further studies. Canadian Society of Forensic Science Journal. 2015;48:122-136.

48. Bhaloo ZM, Yamashita B, Wilkinson D, Daeid NN. The recovery of fingerprints from fired cartridge cases: a comparison of current methods of development with an electrostatic deposition technique. Identification Canada. 2010;33:88-102.

49. Liu S, Pflug M, Hofstetter R, Taylor M. The effect of $\mathrm{pH}$ on electrolyte detection of fingermarks on cartridge cases and subsequent microscopic examination. J Forensic Sci. 2015;60:186-192.

50. Jasuja OP, Singh G. Development of latent fingermarks on thermal paper: preliminary investigation into use of iodine fuming. Forensic Sci Int. 2009;192:e11-e16.

51. Jasuja OP, Kaur A, Kumar P. Fixing latent fingermarks developed by iodine fuming method: a new method. Forensic Sci Int. 2012;223:e47-e52.

52. Braasch K, de la Hunty M, Deppe J, Spindler X, Cantu AA, Maynard P, Lennard C, Roux C. Nile red: Alternative to physical developer for the detection of latent fingermarks on wet porous surfaces? Forensic Sci Int. 2013;230:74-80.
53. Thomas P, Farrugia K. An investigation into the enhancement of fingermarks in blood on paper with genipin and lawsone. Sci Justice. 2013;53:315-320.

54. Frick AA, Busetti F, Cross A, Lewis SW. Aqueous Nile blue: a simple, versatile and safe reagent for the detection of latent fingermarks. Chem Commun. 2014;50:3341-3343.

55. Fritz P, van Bronswijk W, Lewis SW. A new p-dimethylaminocinnamaldehyde reagent formulation for the photoluminescence detection of latent fingermarks on paper. Forensic Sci Int. 2015;257:20-28.

56. Dominick AJ, Daeid NN, Bleay SM. The recoverability of fingerprints on nonporous surfaces exposed to elevated temperatures. J For Ident. 2011;61:520-536.

57. Badiye A, Kapoor N. Efficacy of Robin ${ }^{\circledR}$ powder blue for latent fingerprint development on various surfaces. Egypt J Forensic Sci.. 2015;5:166-173.

58. Dominick AJ, Laing K. A comparison of six fingerprint enhancement techniques for the recovery of latent fingerprints from unfired cartridge cases. J For Ident. 2011;61:155-165.

59. Rawji A, Beaudoin A. Oil red O versus physical developer on wet papers: a comparative study. J For Ident. 2006;56:33-54.

60. Reynolds AJ, Jones BJ, Sears V, Bowman V. Nano-scale analysis of titanium dioxide fingerprint development powders. Journal of Physics: Conference Series. 2008;126:1-4.

61. Jones BJ, Reynolds AJ, Richardson M, Sears VG. Nano-scale composition of commercial white powders for development of latent fingerprints on adhesives. Sci Justice. 2010;50:150-155.

62. Trapecar M. Finger marks on glass and metal surfaces recovered from stagnant water. Egypt J Forensic Sci.. 2012;2:48-53.

63. Honig M, Yoak J. Oil red O: A comparative performance study. J For Ident. 2016;66:118-133.

64. Piekny J, Knaap W. The use of a dry chemical fire extinguisher for the development of latent fingerprints in marijuana grow operations. J For Ident. 2016;66:92-105.

65. Petretei D, Angyal M. Recovering bloody fingerprints from skin. J For Ident. 2015;65:813-827.

66. Perry H, Sears VG. The use of natural yellow 3 (curcumin) for the chemical enhancement of latent friction ridge detail on naturally weathered materials. J For Ident. 2015;65:45-66.

67. Richards DA, Thomas JR. Nonporous fluorescent dye stains: a comparative analysis. J For Ident. 2014;64:239-254.

68. Zampa F, Furlan G, Furlan G, Bellizia M, Iuliano G, Ripani L. New forensic perspective for fast blue B: from cannabinoid reagent in toxicology to latent fingerprint developer in drug cases. J For Ident. 2014;64:523-535.

69. Sodhi GS, Kaur J, Garg RK, Kobilinsky L. A Fingerprint powder formulation based on Rhodamine B dye. J For Ident. 2003;53:551-555.

70. Sodhi GS, Kaur J, Garg RK. Fingerprint powder formulations based on organic, fluorescent dyes. J For Ident. 2004;54:4-8.

71. Frick AA, Fritz P, Lewis SW, van Bronswijk W. Sequencing of a modified oil red $\mathrm{O}$ development technique for the detection of latent fingermarks on paper surfaces. J For Ident. 2013;63:369-385.

72. Simmons RK, Deacon P, Farrugia KJ. Water-soaked porous evidence: a comparison of processing methods. J For Ident. 2014;64:157-173.

73. Bentolila A, Reuveny SA, Attias D, Elad ML. Using alginate gel followed by chemical enhancement to recover blood-contaminated fingermarks from fabrics. J For Ident. 2016;66:13-21.

74. Aronson CK. Development of bloody prints on the adhesive side of duct tape. J For Ident. 2011;61:250-259.

75. de Puit M, Koomen L, Bouwmeester M, de Gijt M, Rodriguez C, van Wouw J, de Haan F. Use of physical developer for the visualization of latent fingerprints. J For Ident. 2011;61:166-170.

76. Beaudoin A. Fingerprint staining technique on dark and wetted porous surfaces: oil red O and rhodamine 6G. J For Ident. 2012;62: 315-329.

77. Gaskell C, Bleay SM, Ramadani J. Natural yellow 3: a novel fluorescent reagent for use on grease-contaminated fingermarks on nonporous dark surfaces. J For Ident. 2013;63:274-285. 
78. Olenik J. Dye staining of duct tape: an overlooked procedure. J For Ident. 2015;65:219-221.

79. Fitzi T, Fischer R, Moret S, Becue A. Fingermark detection on thermal papers: proposition of an updated processing sequence. J For Ident. 2014;64:329-350.

80. Fritz P, van Bronswijk W, Dorakumbura B, Hackshaw B, Lewis SW. Evaluation of a solvent free p-dimethylaminobenzaldehyde method for fingermark visualization with a low-cost light source suitable for remote locations. J For Ident. 2015;65:67-90.

81. Beaudoin A. Comparison of ortho-tolidine and amido black for development of blood-based fingerprints on skin. J For Ident. 2012;62:588-601.

82. Babin B. Fingertips: development of friction ridges on a $9 \mathrm{~mm}$ bullet casing. Identification Canada. 2010;33:103-106.

83. Schwarz L, Hermanowski M. The effect of humidity on long-term storage of evidence prior to using cyanoacrylate fuming for the detection of latent fingerprints. J For Ident. 2012;62:227-233.

84. Fieldhouse SJ. An investigation into the use of a portable cyanoacrylate fuming system (SUPERfume ${ }^{\sqrt{\mathbb{R}}}$ ) and aluminum powder for the development of latent fingermarks. J Forensic Sci. 2011;56:1514-1520.

85. Takatsu M, Shimoda O, Teranishi H. Vapor-phase staining of cyanoacrylate-fumed latent fingerprints using p-dimethylaminobenzaldehyde. J Forensic Sci. 2012;57:515-520.

86. Ristova MM, Radiceska P, Bozinov I, Barandovski L. Refreshing the aged latent fingerprints with ionizing radiation prior to the cyanoacrylate fuming procedure: a preliminary study. J Forensic Sci. 2015; doi: 10.1111/1556-4029.13020.

87. Bentolila A, Totre J, Zozulia I, Levin-Elad M, Domb AJ. Fluorescent cyanoacrylate monomers and polymers for fingermark development. Macromolecules. 2013;46:4822-4828.

88. Prete C, Galmiche L, Quenum-Possy-Berry F, Allain C, Thiburce N, Colard T. Lumicyano ${ }^{\mathrm{TM}}$ : a new fluorescent cyanoacrylate for a onestep luminescent latent fingermark development. Forensic Sci Int. 2013;33:104-112.

89. Paine M, Bandey HL, Bleay SM, Willson H. The effect of relative humidity on the effectiveness of the cyanoacrylate fuming process for fingermark development and on the microstructure of the developed marks. Forensic Sci Int. 2011;212:130-142.

90. Nixon C, Almond MJ, Baum JV, Bond JW. Enhancement of aged and denatured fingerprints using the cyanoacrylate fuming technique following dusting with amino acid-containing powders. J Forensic Sci. 2013;58:508-512.

91. Montgomery L, Spindler X, Maynard P, Lennard C, Roux C. Pretreatment strategies for the improved cyanoacrylate development of dry latent fingerprints on nonporous surfaces. J For Ident. 2012;62:517-542.

92. McLaren C, Lennard C, Stoilovic M. Methylamine pretreatment of dry latent fingermarks on polyethylene for enhanced detection by cyanoacrylate fuming. J For Ident. 2010;60:199-222.

93. Hahn W, Ramotowski R. Evaluation of a novel one-Step fluorescent cyanoacrylate fuming process for latent print visualization. J For Ident. 2012;62:179-298.

94. Wilson HD. RAY dye stain versus gentian violet and alternate powder for development of latent prints on the adhesive side of tape. J For Ident. 2010;60:510-523.

95. Cai K, Yang R, Wang Y, Yu X, Liu J. Super fast detection of latent fingerprints with water soluble CdTe quantum dots. Forensic Sci Int. 2013;226:240-243.

96. Wang YF, Yang RQ, Wang YJ, Shi ZX, Liu JJ. Application of CdSe nanoparticle suspension for developing latent fingermarks on the sticky side of adhesives. Forensic Sci Int. 2009;185:96-99.

97. Arshad A, Farrukh MA, Ali S, Khaleeq-ur-Rahman M, Tahir MA. Development of latent fingermarks on various surfaces using $\mathrm{ZnO}$ $\mathrm{SiO}_{2}$ nanopowder. J Forensic Sci. 2015;60:1182-1187.

98. Theaker BJ, Katherine E. Hudson, Frederick J. Rowell. Doped hydrophobic silica nano- and micro-particles as novel agents for developing latent fingerprints. Forensic Sci Int. 2008;174:26-34.
99. Sametband M, Shweky I, Banin U, Mandler D, Almog J. Application of nanoparticles for the enhancement of latent fingerprints. Chem Comm. 2007;52: 1142-1144.

100. Song K, Huang P,Yi C, Ning B, Hu S, Nie L, Chen X, Nie Z. Photoacoustic and colorimetric visualization of latent fingerprints. ACS Nano. 2015; 9:12344-12348.

101. Algarra M, Jimenez-Jimenez J, Miranda MS, Campos BB, MorenoTost R, Rodriguez-Castellon E, da Silva JCGE. Solid luminescent CdSe-thiolated porous phosphate heterostructures. Application in fingermark detection in different surfaces. Surf. Interface Anal. 2013;45: 612-618.

102. Yang R, Lian J. Studies on the development of latent fingerprints by the method of solid-medium ninhydrin. Forensic Sci Int. 2014;242:123-126.

103. Almog J, Levinton-Shamuilov G, Cohen Y, Azoury M. Fingerprint reagents with dual action: color and fluorescence. J Forensic Sci. 2007; $52: 330-334$.

104. Levinton-Shamuilov G, Cohen Y, Azoury M, Chaikovsky A, Almog J. Genipin, a novel fingerprint reagent with colorimetric and fluorogenic activity, part ii: optimization, scope and limitations. J Forensic Sci 2005; 50:1367-1371.

105. Jelly R, Lewis SW, Lennard C, Lim KF, Almog J. Substituted naphthoquinones as novel amino acid sensitive reagents for the detection of latent fingermarks on paper surfaces. Talanta. 2010;82: 1717-1724.

106. Coughlan S. Using acetone to increase visualization of ninhydrindeveloped fingerprints obscured by common pen ink. J For Ident. 2012; 62:330-333.

107. Schwarz L, Heinrich M, Pfannkuch R. Using DFO with molecular sieve: preliminary results. J For Ident. 2013;63:515-524.

108. Goel TL. Developing latent fingermarks on thermal paper: comparison of the 1,2-indanedione-zinc chloride dry contact method to the hot print system. J For Ident. 2015;65:34-43.

109. Jasuja OP, Toofany MA, Singh G, Sodhi GS. Dynamics of latent fingerprints: the effect of physical factors on quality of ninhydrin developed prints- a preliminary study. Sci Justice 2009;49:8-11.

110. Chen CC, Yu YC, Lee HC, Giang YS, Wang SM. Latent fingerprint development on thermal paper using traditional ninhydrin and 1,2-indanedione. J Forensic Sci. 2016;61:219-225.

111. Garg RK, Pal H, Kaur R. Application of new commonly available substance for the visualization of latent finger marks: white cement. Problems of Forensic Sciences. 2014;97:5-13.

112. Garg RK, Kumari H, Kaur R. A new technique for visualization of latent fingerprints on various surfaces using powder from turmeric: a rhizomatous herbaceous plant (Curcuma longa). Egypt J Forensic Sci. 2011;1:53-57.

113. Kumari H, Kaur R, Garg RK. New visualizing agents for latent fingerprints: synthetic food and festival colors. Egypt J Forensic Sci. 2011;1:133-139.

114. Singh GD, Sodhi GS, Jasuja OP. Detection of latent fingerprints on fruits and vegetables. J For Ident. 2006;56:374-381.

115. Scott J. Exploring the potential of phosphorescent fingerprint powder. J For Ident. 2013;63:175-187.

116. Ma R, Bullock E, Maynard P, Reedy B, Shimmon R, Lennard C, Roux $\mathrm{C}, \mathrm{McD}$ onagh A. Fingermark detection on non-porous and semi-porous surfaces using NaYF4:Er,Yb up-converter particles. Forensic Sci Int. 2011;207:145-149.

117. Gurbuz S, Monkul BO, Ipeksac T, Seden MG, Erol M. A systematic study to understand the effects of particle size distribution of magnetic fingerprint powders on surfaces with various porosities. J Forensic Sci. 2015;60:727-736.

118. Mopoung S, Thongcharoen P. Coloured intensity enhancement of latent fingerprint powder obtained from banana peel activated carbon with methylene blue. Scientific Research and Essay. 2009;4:008-012.

119. Low WZ, Khoo BE, Aziz ZBA, Low LW, Teng TT, Abdullah AFL. Application of acid-modified Imperata cylindrica powder for latent fingerprint development. Sci Justice. 2015;55:347-354. 
120. Bramble SK. Separation of latent fingermark residue by thin layer chromatography. J Forensic Sci. 1995;40:969-975.

121. Weyermann C, Roux C, Champod C. Initial results on the composition of fingerprints and its evolution as a function of time by GCMS analysis. J Forensic Sci. 2011;56:102-108.

122. Michalski S, Shaler R, Dorman FL. The evaluation of fatty acid ratios in latent fingermarks by Gas Chromatography/Mass Spectrometry (GC/MS) analysis. J Forensic Sci. 2013;58:S215-S220.

123. Koenig A, Girod A, Weyermann C. Identification of wax esters in latent print residues by gas chromatography-mass spectrometry and their potential use as aging parameters. J For Ident. 2011;61:652-676.

124. Croxton RS, Baron MG, Butler D, Kent T, Sears VG. Development of a GC-MS method for the simultaneous analysis of latent fingerprint components. J Forensic Sci. 2006;51:1329-1333.

125. Girod A, Weyermann C. Lipid composition of fingermark residue and donor classification using GC/MS. Forensic Sci Int. 2014;238:68-82.

126. Mangle MF, Xu X, de Puit M. Performance of 1,2-indanedione and the need for sequential treatment of fingerprints. Sci Justice. 2015;55:343-346.

127. de Puit $\mathrm{M}$, Ismail $\mathrm{M}, \mathrm{Xu} X$. LC-MS analysis of fingerprints, the amino acid profile of 20 donors. J Forensic Sci. 2014;59:364-370.

128. Connatser RM, Prokes SM, Glembocki OJ, Schuler RL, Gardner CW, Lewis SA, Lewis LA. Toward surface-enhanced Raman imaging of latent fingerprints. $J$ Forensic Sci. 2010;55:1462-1470.

129. Song W, Mao Z, Liu X, Lu Y, Li Z, Zhao B, Lu L. Detection of protein deposition within latent fingerprints by surface-enhanced Raman spectroscopy imaging. Nanoscale. 2012;4:2333-2338.

130. Guicheteau JA, Swofford H, Tripathi A, Wilcox PG, Emmons ED, Christesen SD, Wood J, Fountain III AW. Sequential Raman chemical imaging and biometric analysis on fingerprints for rapid identification of threat materials and individuals. J For Ident. 2013;63:90-101.

131. Williams DK, Brown CJ, Bruker J. Characterization of children's latent fingerprint residues by infrared microspectroscopy: Forensic implications. Forensic Sci Int. 2011;206:161-165.

132. Fritz P, van Bronswijk W, Lepkova K, Lewis SW, Lim KM, Martin DE, Puskar L. Infrared microscopy studies of the chemical composition of latent fingermark residues. Microchem J. 2013;111:40-46.

133. Williams DK, Schwartz RL, Bartick EG. Analysis of latent fingerprint deposits by infrared microspectroscopy. Applied Spectroscopy. 2004;58:313-316.

134. Atherton T, Croxton R, Baron M, Gonzalez Rodriguez J, Gámiz-Gracia L, García-Campaña AM. Analysis of amino acids in latent fingerprint residue by capillary electrophoresis-mass Spectrometry. J Separation Sci. 2012;35:2994-2999.

135. Girod A, Ramotowski R, Weyermann C. Composition of fingermark residue: A qualitative and quantitative review. Forensic Sci Int. 2012;223:10-24.

136. Bailey MJ, Bright NJ, Croxton RS, Francese S, Ferguson LS, Hinder S, Jickells S, Jones BJ, Jones BN, Kazarian SG, Ojeda JJ, Webb RP, Wolstenholme R, Bleay S. Chemical characterization of latent fingerprints by Matrix-Assisted Laser Desorption Ionization, Time-of-Flight Secondary Ion Mass Spectrometry, Mega Electron Volt Secondary Mass Spectrometry, Gas Chromatography/Mass Spectrometry, X-Ray Photoelectron Spectroscopy, and Attenuated Total Reflection Fourier Transform Infrared Spectroscopic Imaging: An Intercomparison. Anal Chem. 2012;84:8514-8523.
137. Almog J, Sheratzki H, Elad-Levin M, Sagiv AE, Singh GD, Jasuja OP. Moistened hands do not necessarily allude to high quality fingerprints: The relationship between palmar moisture and fingerprint donorship. J Forensic Sci. 2011;56:S162-S165.

138. Lambrechts SAG, van Dam A, de Vos J, van Weert A, Sijen T, Aalders MCG. On the autofluorescence of fingermarks. Forensic Sci Int. 2012;222:89-93.

139. Emerson B, Gidden J, Lay JO, Durham B. Laser desorption/ionization time-of-flight mass spectrometry of triacylglycerols and other components in fingermark samples. J Forensic Sci. 2011;56:381-389.

140. Ferguson L, Bradshaw R, Wolstenholme R, Clench MR, Francese S. Two-step matrix application for the enhancement and imaging of latent fingermarks. Anal Chem. 2011;83:5585-5591.

141. Ferguson L, Creasey S, Wolstenholme R, Clench MR, Francese S. Efficiency of the dry-wet method for the MALDI-MSI analysis of latent fingermarks. J Mass Spectro. 2013;48:677-684.

142. Francese S, Bradshaw R, Flinders B, Mitchell C, Bleay S, Cicero L, Clench MR. Curcumin: A multipurpose matrix for MALDI mass spectrometry imaging applications. Anal Chem. 2013;85:5240-5248.

143. Bradshaw R, Francese S. Matrix-assisted laser desorption ionisation tandem mass spectrometry imaging of small molecules from latent fingermarks. Spectroscopy Europe. 2014;26:6-8.

144. Bailey MJ, Bradshaw R, Francese S, Salter TL, Costa C, Ismail M, Webb RP, Bosman I, Wolfff K, de Puit M. Rapid detection of cocaine, benzoylecgonine and methylecgonine in fingerprints using surface mass spectrometry. Analyst. 2015;140:6254-6259.

145. Francese S, Bradshaw R, Ferguson R, Wolstenholme R, Clench MR, Bleay S. Beyond the ridge pattern: Multi-informative analysis of latent fingermarks by MALDI mass spectrometry. Analyst. 2013;138:4215-4228.

146. Bradshaw R, Wolstenholme R, Blackledge RD, Clench MR, Ferguson LS, Francese $\mathrm{S}$. A novel matrix-assisted laser desorption/ionisation mass spectrometry imaging based methodology for the identification of sexual assault suspects. Rapid Communications in Mass Spectrometry. 2011;25:415-422.

147. Bradshaw R, Wolstenholme R, Ferguson LS, Sammon C, Mader K, Claude E, Blackledge RD, Clench MR, Francese S. Spectroscopic imaging based approach for condom identification in condom contaminated fingermarks. Analyst. 2013;138:2546-2557.

148. Ferguson L, Bradshaw R, Wolstenholme R, Clench MR, Francese S. Two-step matrix application for the enhancement and imaging of latent fingermarks. Anal Chem. 2011;83:5585-5591.

149. Francese S, Bradshaw R, Flinders B, Mitchell C, Bleay S, Cicero L, Clench MR. Curcumin: A multipurpose matrix for MALDI mass spectrometry imaging applications. Anal Chem. 2013;85:5240-5248.

150. Yagnik GB, Korte AR, Lee YJ. Multiplex mass spectrometry imaging for latent fingerprints. Journal of Mass Spectrometry. 2012;48: 100-104.

151. Bradshaw R, Rao W, Wolstenholme R, Clench MR, Bleay S, Francese S. Separation of overlapping fingermarks by matrix assisted laser desorption ionisation mass spectrometry imaging. Forensic Sci Int. 2012;222:318-326.

152. Ferguson LS, Wulfert F, Wolstenholme R, Fonville JM, Clench MR, Carolan VA, Francese S. Direct detection of peptides and small proteins in fingermarks and determination of sex by MALDI mass spectrometry profiling. Analyst. 2012;137:4686-4692.
Research and Reports in Forensic Medical Science

\section{Publish your work in this journal}

Research and Reports in Forensic Medical Science is an international, peer-reviewed, open access journal publishing original research, reports, reviews and commentaries on all areas of forensic medical science. The manuscript management system is completely online and includes a very quick and fair peer-review system. Visit http://www.dovepress.com/ testimonials.php to read real quotes from published authors. 